\title{
Compressive Membrane Action in FRP-strengthened Concrete Beams
}

\section{Yihua ZENG \\ PhD student, Department of \\ Structural Engineering, \\ UGent, Ghent, Belgium \\ Yihua.Zeng@UGent.be}

Yihua Zeng, born 1987, received

his master degree from the

Southeast Univ. in 2010

\author{
Robby CASPEELE \\ Prof., Department of \\ Structural Engineering, \\ UGent, Ghent, Belgium \\ Robby.Caspeele@UGent.be \\ Robby Caspeele, born 1983, \\ received his doctoral degree from \\ the Ghent Univ. in 2010
}

\author{
Luc TAERWE \\ Prof., Department of \\ Structural Engineering, \\ UGent, Ghent, Belgium \\ Luc.Taerwe@UGent.be \\ Luc Taerwe, born 1952, received \\ his doctoral degree from the \\ Ghent Univ. in 1985
}

\section{Summary}

A comparison of compressive membrane action (CMA) between standard reinforced concrete (RC) members and RC members strengthened with Fibre Reinforced Polymer (FRP) is performed. The comparison is based on an extension of Park and Gamble's model and quantified by defining an enhancement factor. Results indicate that the CMA effect decreases with increasing steel reinforcement for $\mathrm{RC}$ beams whereas this conclusion only holds for the effect of top steel reinforcement in case of FRP-strengthened RC beams. Results also show that the CMA effect increases with increasing concrete strength and is not significantly affected by span-to-depth ratio for both beam systems.

Keywords: Compressive membrane action; reinforced concrete; fibre reinforced polymers.

\section{Introduction}

Since compressive membrane action (CMA) has been recognized for laterally restrained members, research results have shown that CMA is beneficial in strength enhancement. With regard to the investigation of CMA in concrete members, a commonly applied proposed by Park and Gamble [1], is used here using plastic theory to consider CMA by performing analysis of strain compatibility and force equilibrium. With the increased application of Fibre Reinforced Polymer (FRP) to strengthen concrete structures, it is desirable to conduct a comparison of CMA between standard concrete members and FRP-strengthened concrete members.

The aim of this study is to investigate the differences of CMA between standard reinforced concrete (RC) members and FRP-strengthened RC members

\section{Extension of Park and Gamble's model}

\subsection{Assumptions}

According to Park and Gamble's method, a model with four idealized plastic hinges formed symmetrically along the beam is chosen to represent a standard RC beam or a FRP-strengthened RC beam. A perfectly rigid plastic mechanism is basically assumed. A complete symmetry along the span is assumed with respect to geometry, reinforcement, loading, boundary conditions and deformations. The lateral restraints are idealized to be equivalent axial springs

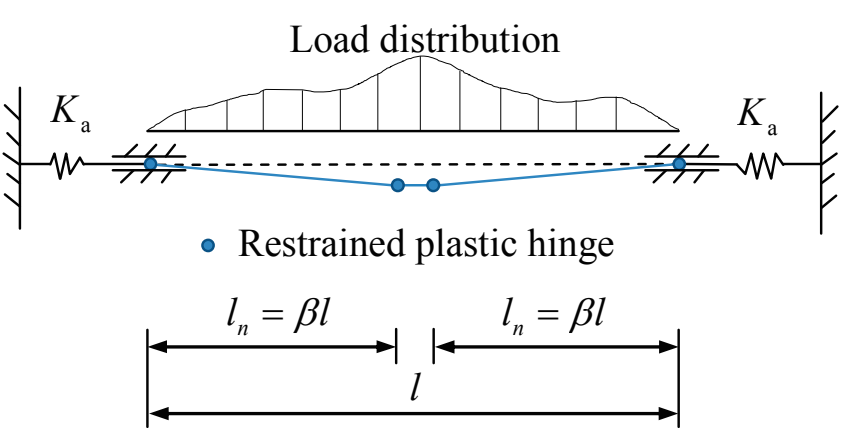

Fig. 1: Schematic view of a laterally restrained 
with stiffness $K_{\mathrm{a}}$. Fig. 1 shows the schematic view of the model, where $\beta$ is the ratio of the span length $l_{\mathrm{n}}$ from the plastic hinge at the beam end to the nearest hinge in the span to the beam span $l$.

The widely-adopted assumptions such as the assumptions of plane-section, a full composite action of FRP and an equivalent rectangular stress block for compressive concrete are considered to perform the analysis of compatibility and force equilibrium [2]. Note that the full composite action of FRP means that a failure occurs when the tensile steel reinforcement has yielded followed by concrete crushing whereas the FRP remains intact. Further, the axial force at the beam end $\left(N_{\mathrm{u} 1}\right)$ is assumed to be equal to the axial force in the $\operatorname{span}\left(N_{\mathrm{u} 0}\right)$, as show in Eq. (1)

$$
N=N_{\mathrm{u} 0}=N_{\mathrm{u} 1}
$$

Besides, the compressive strain of the beam is assumed to be uniformly distributed along the beam length with a value of $\varepsilon=N /\left(E_{\mathrm{c}} A_{\mathrm{c}}\right)$, where $N$ is the axial force, $E_{\mathrm{c}}$ is elastic modulus of concrete and $A_{\mathrm{c}}$ is the cross-sectional area.

\subsection{Model prediction and verification}

Fig. 2 shows one-half of the deformed shape. The axial force along the beam causes a horizontal displacement at each support, $t$ $=N / K_{\mathrm{a}}$. Due to the uniform compression strain along the beam, the contraction of the portion in Fig. 2 is $\varepsilon \beta l$ and the contraction of the middle portion is $(1-2 \beta) \varepsilon l$. For a given beam deflection $\delta$, we have $\tan \theta \approx \delta / \beta l$ assuming that the rotation at the beam end $\theta$ is so small that $\sin \theta \approx \theta$ and $\cos \theta \approx$ 1 hold. Recalling the expressions of the beam strain $\varepsilon$ and lateral restraint deformation $t$, the

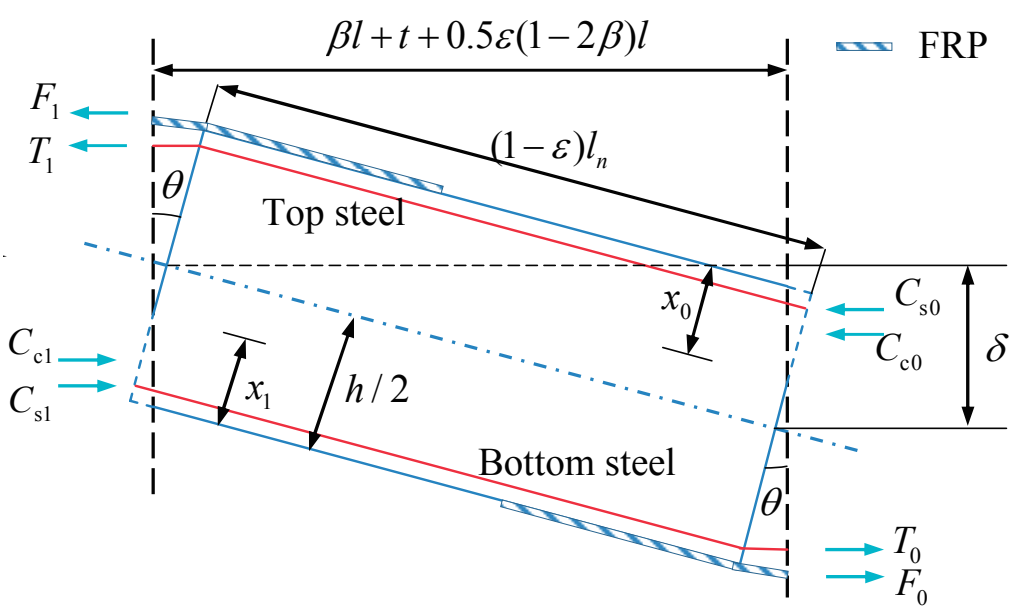

Fig. 2 Idealized deformation of one-half of the restrained beam compatibility requirement can be expressed as in Eq. (2)

$$
h-x_{0}-x_{1}=\frac{\delta}{2}+\frac{N \beta l^{2}}{2 \delta}\left(\frac{1}{E_{\mathrm{c}} A_{\mathrm{c}}}+\frac{2}{K_{\mathrm{a}} l}\right)
$$

where $x_{0}$ and $x_{1}$ are the neutral-axis depth in the span and at the beam ends, respectively; $h$ is the beam depth. According to Fig. 2, Eq. (1) can be rewritten as

$$
C_{\mathrm{c} 0}+C_{\mathrm{s} 0}-T_{0}-F_{0}=C_{\mathrm{c} 1}+C_{\mathrm{s} 1}-T_{1}-F_{1}
$$

where $C_{\mathrm{c} 0}$ and $C_{\mathrm{c} 1}$ are the concrete compressive forces, $C_{\mathrm{s} 0}$ and $C_{\mathrm{s} 1}$ the steel compressive forces, $T_{0}$ and $T_{1}$ the steel tensile forces, and $F_{0}$ and $F_{1}$ the FRP tensile forces, acting on sections at the midspan and the beam end, respectively.

Considering that all terms in Eq. (3) can be expressed by given geometric and material properties and the unknowns $x_{1}$ and $x_{0}$ based on a sectional force equilibrium analysis, $x_{0}$ and $x_{1}$ are obtained by solving the Eqs. (2) and (3) simultaneously for a given $\delta$. Further, the moments at the midspan and the beam ends can be calculated and the load bearing capacity can be calculated. When repeating such procedures for different values of $\delta$, a series of the load bearing capacities are obtained, and the maximum value can be seen as the ultimate load bearing capacity.

Note that, according to the assumed failure mode, the concrete compressive strain reaches to its 
ultimate strain, the steel tensile strain exceeds its yield strain, and the strain of FRP is less than its ultimate strain. In this paper, the ultimate concrete strain is $3.5 \%$ [2], the steel yield strain is calculated by its yield stress, and the ultimate strain of FRP is based test result. In addition, the lateral stiffness is calculated based on the adjacent structural elements.

To verify the extensive model, a standard RC beam (A1) from [3] and a FRP-strengthened RC beam (FR-1) from [4] were selected, each of which can be idealized as the model shown in Fig. 1. The results show that the load bearing capacity is $181.8 \mathrm{kN}$ and $146.6 \mathrm{kN}$ for A1 and FR-1, respectively. This yields an acceptable $8 \%$ and $1 \%$ overestimation compared to the tested results of $168.0 \mathrm{kN}$ and $145.5 \mathrm{kN}$, for A1 and FR-1, respectively, which validates the extended model for FRP-strengthened RC beams.

\section{Comparison of CMA between standard RC beams and FRP-strengthened RC beams}

Considering that CMA is affected by many influencing factors, it is necessary to select a dimensionless quantity to carry out the comparison of CMA between standard RC beams and FRPstrengthened RC beams. Therefore, a strength enhancement factor $\alpha_{\mathrm{P}}$ is adopted and defined as $\alpha_{\mathrm{P}, \mathrm{CMA}, \mathrm{RC}}=P_{\mathrm{CMA}, \mathrm{RC}} / P_{0}$ and $\alpha_{\mathrm{P}, \mathrm{CMA}, \mathrm{FRP}}=P_{\mathrm{CMA}, \mathrm{FRP}} / P_{0, \mathrm{FRP}}$, where $\alpha_{\mathrm{P}, \mathrm{CMA}, \mathrm{RC}}$ and $\alpha_{\mathrm{P}, \mathrm{CMA}, \mathrm{FRP}}$ are enhancement factors quantifying the CMA effect, $P_{\mathrm{CMA}, \mathrm{RC}}$ and $P_{\mathrm{CMA}, \mathrm{FRP}}$ are the beam peak resistances considering CMA calculated by the extensive method, $P_{0}$ and $P_{0, \mathrm{FRP}}$ are the beam peak resistances calculated by fib bulletin 14 [2], each time for standard RC beams and FRP-strengthened $\mathrm{RC}$ beams, respectively.

A beam similar to the four-point loaded two-span beam in [5] is adopted as the benchmark beam in the parametric study. This $10 \mathrm{~m}$ beam is assumed to be laterally restrained $\left(K_{\mathrm{a}}=10^{6} \mathrm{kN} / \mathrm{m}\right)$ at both ends with a $200 \times 400 \mathrm{~mm}$ section and a value of 0.20 for $\beta$ is selected. C30/37 concrete is used and three steel bars are initially placed along the beam length at both the beam top $\left(2 \phi 12+1 \phi 18, A_{\text {top }}=\right.$ $\left.480.4 \mathrm{~mm}^{2}\right)$ and the beam bottom $\left(2 \phi 12+1 \phi 20, A_{\text {bottom }}=540.1 \mathrm{~mm}^{2}\right)$. The elastic modulus and the yield stress of the steel bars are $200 \mathrm{GPa}$ and $500 \mathrm{MPa}$, respectively. In cases of FRP strengthening, a CFRP layer with a section area of $120 \mathrm{~mm}^{2}$ is applied along the beam at tension zones and the elastic modulus and the ultimate strain of the FRP are considered $190 \mathrm{GPa}$ and $1.5 \%$, respectively. All these values apply if no further information is indicated.

\subsection{Effect of steel reinforcement}

Considering the steel reinforcements at both top and bottom of the beam may have different effects on CMA, the effects of the steel reinforcement at the top and at the bottom are investigated separately, which is performed by consecutively fixing the area of steel bars at the bottom or that at the top. Fig. 3 shows the results of the effect of steel reinforcement on CMA for RC beams and FRP-strengthened RC beams.

A first conclusion from Fig. 3 is that that CMA is very significant in improving the beam strength. Taking the standard RC beam for example, a very significant strength increase of $40 \%$ can be obtained, compared to the benchmark beam, when CMA is taken into account. Fig. 3 also shows both the increase of the top steel bars and that of the bottom steel bars contribute to a linear decrease of the enhancement factor for standard RC beams, which implies that, in the general cases of CMA for standard RC beams, the more steel reinforcement is placed, the less the load bearing capacity is affected by CMA. However, for FRP-strengthened RC beams the increase of bottom steel reinforcement contributes to an increase of the enhancement factor. Note that, when the steel reinforcement increases, the decrease of the enhancement factor does not mean that the beam resistance decreases but means the increase rate of the beam resistance due to CMA is smaller than the increase rate of the beam resistance due to the increasing steel reinforcement.

As shown in Fig. 3, another difference of CMA between these two beam systems can be seen: the 
influence of steel reinforcement on the beam resistance capacity under CMA in FRP-strengthened $\mathrm{RC}$ beams is less significant than that in standard RC beams. For instance, in cases where the top steel reinforcement is 0.4 times the $A_{\text {top }}$, the enhancement factor are 1.59 and 1.14 for the standard RC beam and the FRP-strengthened RC beam, respectively, which implies a 39\% more enhancement due to CMA is obtained for the standard RC beam than the FRP-strengthened RC beam.
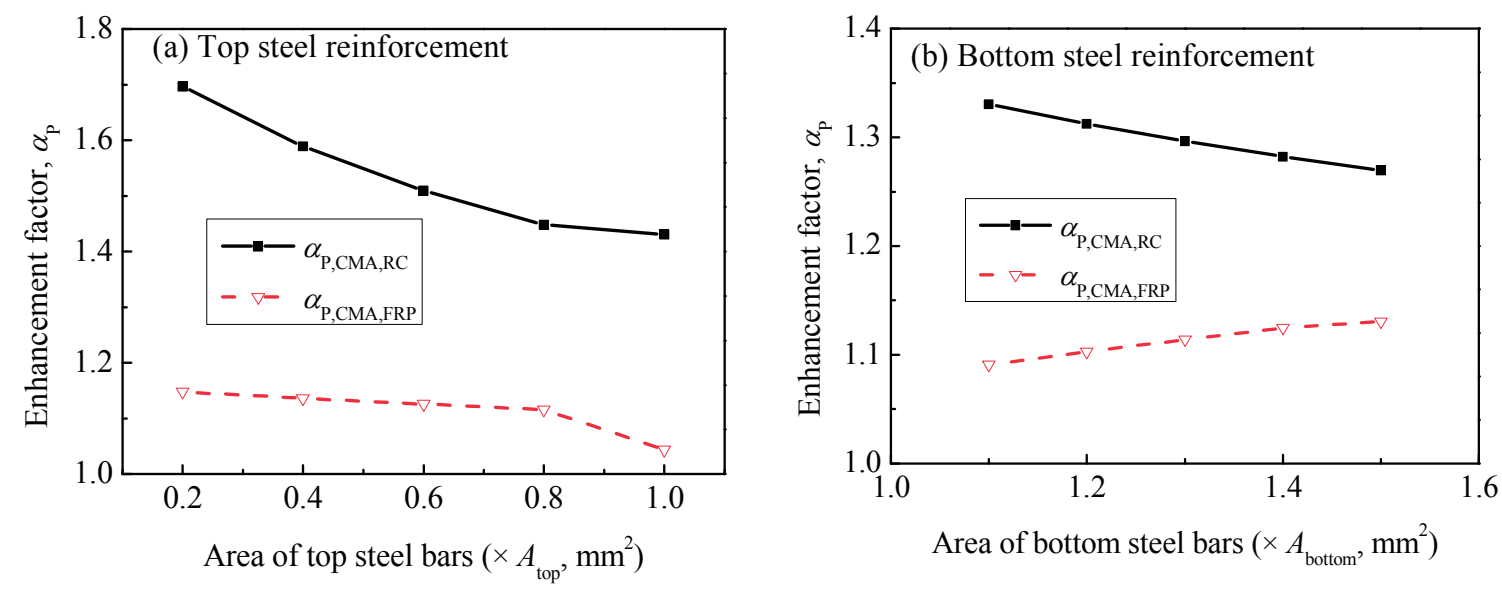

Fig. 3 Effect of steel reinforcement

Also, the decrease of the enhancement factor due to the increase of top steel reinforcement in standard RC beams is more significant that in FRP-strengthened RC beams given that the slope of $\alpha_{\mathrm{P}, \mathrm{CMA}, \mathrm{RC}}$ is smaller than that of $\alpha_{\mathrm{P}, \mathrm{CMA}, \mathrm{FRP}}$.

\subsection{Effect of concrete strength and span-to-depth ratio}

The comparison of the CMA effect between conventional RC beams and FRP-strengthened RC beams was further conducted by investigating the effects of concrete strength and span-to-depth ratio on CMA, as shown in Fig. 4 and Fig. 5, respectively. In Fig. 4, it can be seen that the enhancement factor increases with increasing concrete strength $\left(f_{\mathrm{ck}} \leq 50 \mathrm{MPa}\right)$ for both standard RC beams and FRP-strengthened RC beams. Also, both the effect of CMA on the enhancement of the beam strength and the effectiveness of the effect of the increasing concrete strength in enhancing the beam strength in FRP-strengthened RC beams is less significant than that in standard RC beams. Fig. 5 shows that the span-to-depth ratio does not influence the enhancement factor for both standard RC beams and RFP-strengthened RC beams. This means the load bearing capacity considering CMA decreases to the same relative amount as the decrease of the load bearing capacity without the consideration of CMA when the span-to-depth ratio increases.

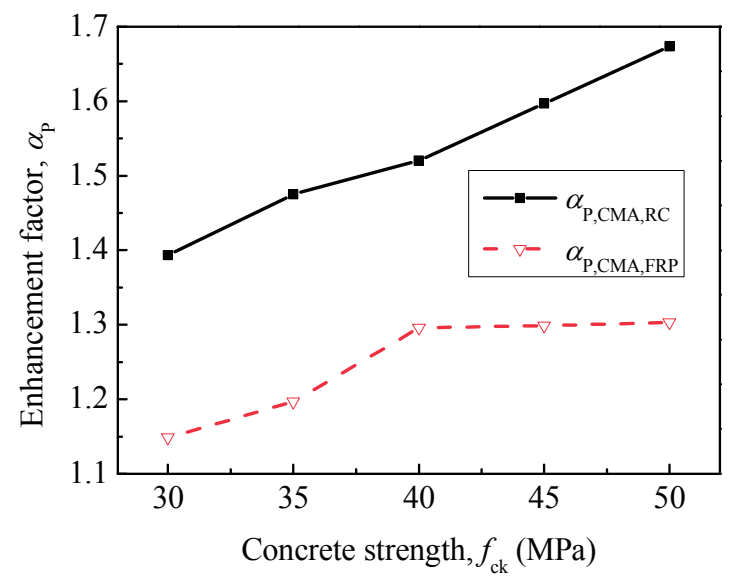

Fig. 4 Effect of concrete strength

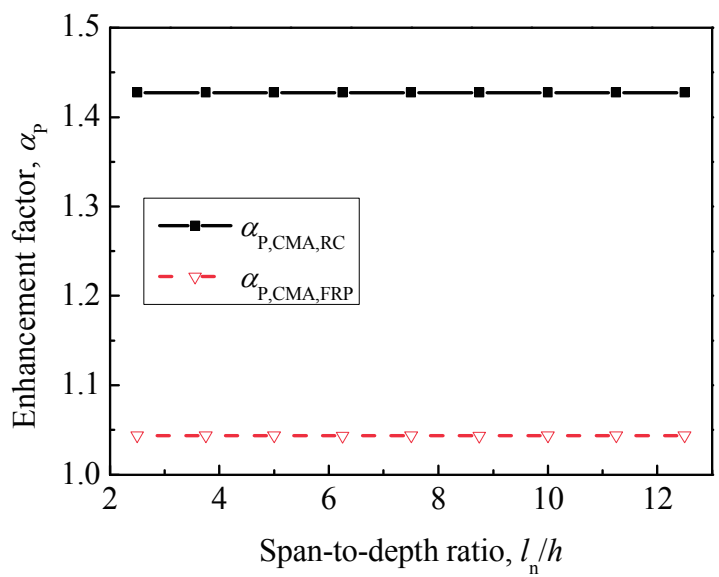

Fig. 5 Effect of span-to-depth ratio 


\section{Conclusion}

Park and Gamble's method to investigate the compressive membrane action (CMA) was first extended and verified to enable the analysis of CMA in FRP-strengthened RC members. Comparisons of the CMA effect on load bearing capacity between standard RC beams and FRPstrengthened RC beams were then conducted by defining a dimensionless enhancement factor as the ratio of the beam resistance considering CMA to the beam resistance without the consideration of CMA. Results indicate that the CMA effect decreases with increasing steel reinforcement for RC beams whereas this conclusion in case of FRP-strengthened RC beams only holds for the effect of top steel reinforcement on CMA. An interesting finding is that, the decrease of the enhancement factor due to the decrease of top steel reinforcement in standard RC beams is more significant that in FRP-strengthened RC beams Results also show that the CMA effect increases with increasing concrete strength and is not significantly affected by span-to-depth ratio for both the RC and FRPstrengthened RC beam systems.

\section{Acknowledgements}

The authors would like to acknowledge the financial support from the China Scholarship Council (No. 201306090135).

\section{References}

[1] PARK R., GAMBLE W.L., Reinforced Concrete Slabs, John Wiley, New York, 2000. p. 736.

[2] fib bulletin 14. Externally Bonded FRP Reinforcement for RC Structure, fib, Lausanne, Switzerland; 2001. p. 146.

[3] SU Y.P., TIAN Y., SONG X.S., "Progressive Collapse Resistance of Axially-Restrained Frame Beams”, ACI Structural Journal, Vol. 106, No. 5, 2009, pp. 600-607.

[4] ORTON S., JIRSA J.O., BAYRAK O., "Carbon Fibre-Reinforced Polymer for Continuity in Existing Reinforced Concrete Buildings Vulnerable to Collapse", ACI Structural Journal, Vol 106, No. 5, 2009, pp. 608-616.

[5] VASSEUR L., MATTHYS S., TAERWE L., "Analytical Study of a 2-span Reinforced Concrete Beam Strengthened with Fibre Reinforced Polymer", IABSE Symposium Report, Budapest, Hungary, Vol. 92, No. 10, 2006, pp. 39-46. 